\title{
Intraoperative non-technical skills: a critical target for improving surgical outcomes
}

\author{
Kara Vande Walle, Caprice Greenberg
}

Department of Surgery, University of Wisconsin, Madison, Wisconsin, USA

\section{Correspondence to} Dr Caprice Greenberg, Department of Surgery, University of Wisconsin, 600 Highland Avenue, Madison, USA;

greenberg@surgery.wisc.edu

Accepted 29 September 2017 Published Online First 9 October 2017

\section{SLinked}

http://dx.doi.org/10.1136/ bmjqs-2017-006701

Check for updates

To cite: Vande Walle $\mathrm{K}$ Greenberg C. BMJ Qual Saf 2018;27:99-101.
Surgical performance is a function of technical and non-technical skills, the latter of which encompasses both cognitive and interpersonal skills. ${ }^{1}$ The important role of intraoperative non-technical skills in determining surgical safety and outcomes has been increasingly recognised in recent years. To that end, in this issue, Sexton et $a l^{2}$ evaluate the non-technical skills of teamwork and situation awareness. Specifically, they examine the effect of team anticipation on operative time and cognitive load in the environment of robotic surgery. Through analysis of video and audio from 12 robot-assisted radical prostatectomies, they were able to calculate anticipation ratios (per cent of requests that were non-verbal) and investigate the impact on surgical performance. While increased anticipation led to decreased operating room time, it also increased the assistant surgeon's cognitive workload. ${ }^{2}$ Prior work has shown that increased cognitive load is associated with errors and poorer performance, which demonstrates the complexity of this important domain of intraoperative performance. ${ }^{3}$ While increased anticipation may improve overall efficiency, these data suggest it may also increase system and team vulnerability to adverse events if not carefully managed.

It is postulated that the ability to anticipate a team member's needs reflects a shared mental model. Shared mental models are common or overlapping cognitive representations of task requirements, procedures and role responsibilities. ${ }^{4}$ Mental models help team members describe, explain and predict events in their environment. ${ }^{5}$ A team with a shared mental model predicts the future state throughout the operation and anticipates events and the needs of others. This makes the operation efficient, as seen in the decreased operative times in Sexton et $a l^{2}$ Conversely, if a team did not have the same mental model, different future states could be predicted. The team is less likely to be working towards the same objectives, which can lead to conflict and inefficiencies.

While anticipation can be helpful in improving operating room efficiency, which represents an important aspect of surgical quality, it may take cognitive effort on behalf of the team members. To measure cognitive load, the authors of this study used the National Aeronautics and Space Administration-Task Load Index. This validated tool uses self-ratings of mental demand, physical demand, temporal demand, effort, performance and frustration. Sexton $e t a^{2}$ demonstrate that an increased anticipation ratio was associated with an increase in the cognitive workload of the assistant surgeon. This may be explained by an increased cognitive effort required by the assistant surgeon to be proactive rather than reactive. While efficiency is important, a critical next step in this research is to investigate the impact of this increased cognitive demand on safety, another core aspect of surgical quality.

Yurko et $a l^{3}$ demonstrated that increased cognitive load is associated with an increase in errors and a decrease in performance. One way to prevent this unintended safety compromise is to identify opportunities to decrease cognitive load in other less critical operating room tasks, which can create space to increase the cognitive load associated with important tasks such as anticipation and enhanced teamwork as described in this study. To achieve this, we should focus on finding and optimising the modifiable contributors to cognitive load. Previous research has identified intrinsic 
patient factors, such as obesity or aberrant anatomy, as factors that increase cognitive load but are not modifiable. ${ }^{6}$ Other works suggest that cognitive load can be decreased through simulation, experience and standardisation, ${ }^{78}$ providing several potential interventions to optimise cognitive load. While there has been limited investigation in the operating room, distractions during complex tasks (such as driving) have been identified as another contributor to increased cognitive load. ${ }^{9}$ Distractions in the operating room represent an actionable target for intervention that could decrease cognitive load with a low risk of negative implications for other aspects of quality.

The surgical instrument count provides a case to illustrate the importance of cognitive load and how system interventions can modify it. In a 2006 study investigating patient safety in the operating room, auxiliary tasks (defined as tasks that are not patient-centred) were disruptive to team members and increased system vulnerability. ${ }^{10}$ One prevalent source of disruption was the manual surgical instrument and sponge count done by the nurses. During counting activities, responses to requests made by the surgeon were delayed and safety-comprising events that were attributable to multiple competing tasks causing increased cognitive load were identified. ${ }^{11}$ Specifically, the system-imposed increase in cognitive load on the nurses during the surgical count introduced unintended errors and inefficiencies into the system. The process of the surgical count is modifiable. One solution is to perform the count at less critical portions of the operative case, a phenomenon known as workload levelling. Another is to supplement the oral count with adjunct technology such as radiofrequency, radiofrequency identification or barcoded surgical sponges. ${ }^{12}$ Through standardisation and off-loading of responsibility to technology rather than personnel, such automation can decrease cognitive load for team members, reserving it for more critical aspects of the case such as the anticipation described by Sexton and colleagues. ${ }^{2}$

Non-technical skills in the operating room remain essential targets to improve surgical quality, including safety and efficiency. The study by Sexton et $a l^{2}$ highlights the importance of non-technical skills, including situation awareness, communication and teamwork. However, current knowledge of the effect of intraoperative non-technical skills remains remarkably superficial. How teams function in the operating room and how they interact with the system around them is a dynamic and complex process, and there are several steps that need to be taken to better understand the mechanisms and effects of non-technical skills.

First, we need to recognise the importance of engaging other disciplines in our investigations. Experts such as systems engineers, human factors engineers, cognitive psychologists and organisational psychologists have been studying these issues in equally high-risk fields. Applying their methodology and theoretical frameworks to the operating room will be essential to our success in understanding and improving non-technical skills in the operating room. Next, we need more intraoperative fieldwork. This includes both live intraoperative observations and the use of audiovisual equipment in the operating room, as illustrated in the study by Sexton et al and others. ${ }^{2} 13$ Through intraoperative fieldwork, we can gather rich data for both qualitative and quantitative analyses to advance our understanding of the role non-technical skill plays in surgical outcomes ${ }^{14} 15$ and create interventions to improve non-technical skills in the operating room.

As we strive to become high-reliability healthcare organisations, the value of optimising non-technical skills becomes increasingly clear. Studies such as this one are a step in the right direction to a deeper understanding of the complexity of intraoperative non-technical skills.

\section{Competing interests None declared.}

Provenance and peer review Commissioned; internally peer reviewed.

(C) Article author(s) (or their employer(s) unless otherwise stated in the text of the article) 2018. All rights reserved. No commercial use is permitted unless otherwise expressly granted.

\section{REFERENCES}

1 Flin R, Yule S, Paterson-Brown S, et al. Teaching surgeons about non-technical skills. Surgeon 2007;5:86-9.

2 Sexton K, Johnson A, Gotsch A, et al. Anticipation, teamwork and cognitive load: chasing efficiency during robot-assisted surgery. BMJ Qual Saf 2018;27:148-54.

3 Yurko YY, Scerbo MW, Prabhu AS, et al. Higher mental workload is associated with poorer laparoscopic performance as measured by the NASA-TLX tool. Simul Healthc 2010;5:267-71.

4 Cannon-Bowers JA, Salas E, Converse SA. In: Castellan J, ed. Individual and group decision making. New Jersey: Lawrence Erlbaum Associates, 1993. Shared mental models in expert team decision making.

5 Mathieu JE, Heffner TS, Goodwin GF, et al. The influence of shared mental models on team process and performance. $J$ Appl Psychol 2000;85:273-83.

6 Ruiz-Rabelo JF, Navarro-Rodriguez E, Di-Stasi LL, et al. Validation of the NASA-TLX Score in Ongoing Assessment of Mental Workload During a Laparoscopic Learning Curve in Bariatric Surgery. Obes Surg 2015;25:2451-6.

7 Tien T, Pucher PH, Sodergren MH, et al. Differences in gaze behaviour of expert and junior surgeons performing open inguinal hernia repair. Surg Endosc 2015;29:405-13.

8 Sweller J. Element interactivity and intrinsic, extraneous, and germane cognitive load. Educ Psychol Rev 2010;22:123-38.

9 Horberry T, Anderson J, Regan MA, et al. Driver distraction: the effects of concurrent in-vehicle tasks, road environment complexity and age on driving performance. Accid Anal Prev 2006;38:185-91. 
10 Christian CK, Gustafson ML, Roth EM, et al. A prospective study of patient safety in the operating room. Surgery 2006;139:159-73.

11 Dierks MM, Christian CK, Roth EM, et al. Healthcare Safety: The Impact of Disabling "Safety" Protocols. IEEE Transactions on Systems, Man, and Cybernetics - Part A: Systems and Humans 2004;34:693-8.

12 Greenberg CC, Diaz-Flores R, Lipsitz SR, et al. Bar-coding surgical sponges to improve safety: a randomized controlled trial. Ann Surg 2008;247:612-6.
13 Bonrath EM, Gordon LE, Grantcharov TP. Characterising 'near miss' events in complex laparoscopic surgery through video analysis. BMJ Qual Saf 2015;24:516-21.

14 Robertson ER, Hadi M, Morgan LJ, et al. Oxford NOTECHS II: a modified theatre team non-technical skills scoring system. PLoS One 2014;9:e90320.

15 Morgan L, Pickering SP, Hadi M, et al. A combined teamwork training and work standardisation intervention in operating theatres: controlled interrupted time series study. BMJ Qual Saf 2015;24:111-9. 